\title{
Application of a CC-VSI for Active Filtering and Photovoltaic Energy Conversion with a 1-to-1 MPPT controller
}

\author{
Hanny H. Tumbelaka ${ }^{1}$, Masafumi Miyatake ${ }^{2}$ \\ ${ }^{1}$ Department of Electrical Engineering \\ Petra Christian University, Surabaya, Indonesia \\ ${ }^{2}$ Department of Engineering and Applied Sciences \\ Sophia University, Tokyo, Japan \\ E-mail: tumbeh@petra.ac.id
}

\begin{abstract}
This paper focuses on the implementation of a three-phase four wire current-controlled Voltage Source Inverter (CC-VSI) as both PV energy extraction and power quality improvement. For power quality improvement, the CC-VSI works as a grid current-controller shunt active power filter. Then, the PV array supported by a Look-up Table type of a MPPT controller is coupled to the DC bus of the CC-VSI. The output of MPPT controller is a DC voltage that determines the DC-bus voltage according to the PV maximum power. The computer simulation results show that the system works properly in steady state and dynamic condition.
\end{abstract}

Keywords: active power filter, MPPT, PV energy conversion

\section{INTRODUCTION}

AC-DC power conversion is very common in electric power utilization. In converting power between the two forms, an AC side is often an AC load or can be a voltage source from a power utility, or a generator. On the other hand, a DC side is generally connected to a DC load or, in many applications, a power source such as batteries and photovoltaic panels.

In order to control the desired power flow between the DC side and the AC side, a Voltage Source Inverter (VSI) is usually applied. In the VSI, an Insulated Gate Bipolar Transistor (IGBT) with an anti-parallel diode is frequently used as a switch. Nowadays, power flow control in the VSI can be achieved using a currentcontrol technique. By controlling the switching instants, the current-controlled VSI (CC-VSI) produces the desired current flow using instantaneous current feedback [1].

For applications, A CC-VSI can be used to transfer active power from a renewable energy source such as solar energy to the AC grid (grid-connected PV system), as well as to the loads [2-4].

The AC side of the CC-VSI attaches to the utility grid at the point of common coupling (PCC), while the DC side

Note: Discussion of this paper must be submitted before December $1^{\text {st }}, 2008$. The proper discussion will be published in Electrical Engineering Journal volume 9, number 1, March 2009. of the CC-VSI is connected to PV panels. To maximize the extracted power flow from the PV panels, a maximum power point tracking (MPPT) algorithm is commonly applied.

A CC-VSI can also be applied as a shunt active power filter (APF) to improve the power quality of the power system [5-7]. The power converter operates to cancel the harmonics, as well as reactive power from the nonlinear loads so that the grid currents will be sinusoidal with unity power factor. The AC side of the CC-VSI attaches to the AC grid at the PCC and parallel with the loads, while the DC bus of the CC-VSI contains a DC capacitor.

Since the CC-VSI for transferring active power and for active filtering has a similar configuration, it is potential to combine both functions in one CC-VSI. In this way, the power converter would be able to improve the system power quality as well as to deliver energy from renewable energy sources.

There are few literatures that discuss about combining PV power extraction and active filtering [8-9]. However, this paper proposes a simple and integrated method for the CC-VSI to supply extracted power from renewable energy sources especially PV panels to the grid/load as well as to mitigate and regulate the harmonic and reactive power injected into the utility grid. 


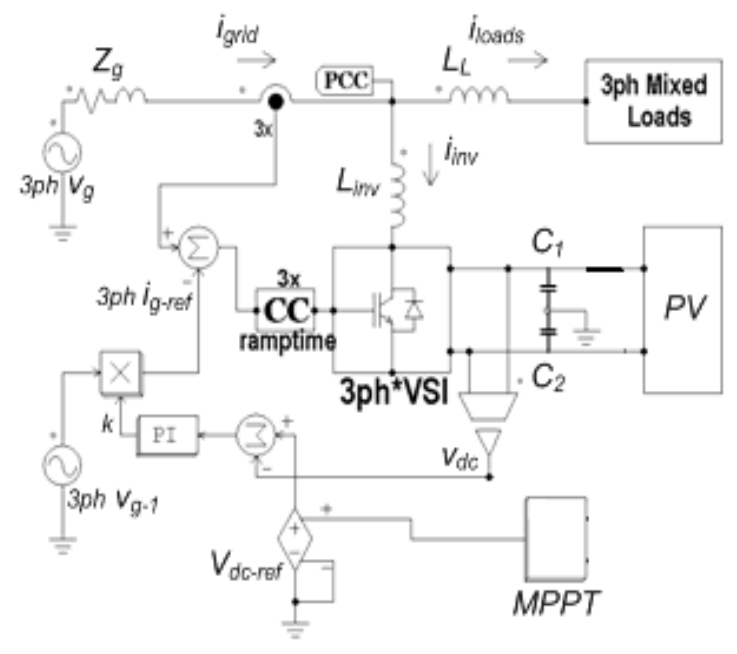

Figure 1 . The proposed CC-VSI configuration

\section{THE CC-VSI}

The three-phase four-wire CC-VSI for active filter and $\mathrm{PV}$ energy conversion is essentially three independent single-phase inverters with a common DC bus. There are a mid-point earthed split capacitor at the DC-bus and inductors at the AC side. It consists of a current control loop and a voltage control loop [6-7]. The speed of response of the voltage control loop is much slower than that of the current control loop. Hence, the current control loop and voltage control loop are decoupled. Figure 1 shows the proposed CC-VSI configuration.

\section{Current Control Loop}

The current control loop shapes the grid currents, rather than VSI currents, to be sinusoidal by generating a certain pattern of bipolar PWM for continuous switching of the power converter switches according to ramptime current control technique[1]. The principle operation of ramptime current control is similar to a sliding mode control and based on the concept of zero average current error (ZACE) with a constant switching frequency.

In this case, the current sensors are located on the grid side. The grid currents are sensed and directly controlled to follow symmetrical sinusoidal reference signals, which is in-phase with the grid voltages. Hence, the outputs of the sensors are compared to the reference signals. The current error signals, which are the differences between the actual currents (grid currents $-i_{q}$ ) and the reference signals $-i_{\text {gref }}$, are processed using ramptime current control to generate PWM signals for driving the power switches. Therefore, by forcing the grid currents to be identical to the reference signals, the CC-VSI operates as a shunt active power filter (APF) and automatically provides the harmonic, reactive, negative- and zerosequence currents for the load according to the basic current summation rule (equation 1) without measuring and determining the unwanted load current components.

$i_{\text {grid }}=i_{\text {inv }}+i_{\text {loads }}$

\section{Voltage Control Loop}

The voltage control loop is a simple Proportional Integral (PI) control to keep the DC-bus voltage at the reference voltage level $\left(V_{d c-r e f}\right)$ and to provide the magnitude of reference current signals $\left(i_{g-r e f}\right)$. In this loop, the active power is maintained balanced among the grid, the load and the DC bus of the VSI.

If active power unbalance occurs in the system, there is a voltage deviation $\left(\Delta V_{d c}\right)$ in the DC bus relative to the reference voltage. The voltage control loop responds to adjust the amplitude of grid active currents appropriately as well as to recover the DC-bus voltage to the reference voltage level. The output of the PI controller, which is a gain $k$, can determine the amount of $\Delta V_{d c}$ that corresponds to the grid current amplitude. The average DC-bus voltage is then recovered and stays at the reference voltage. At steady state, $\Delta V_{d c}$ will be equal to zero. New steady state active power balance has been achieved with new grid current amplitude. The sinusoidal grid current reference signal is given by $\mathrm{i}_{\text {g-ref }}=\mathrm{k} \mathrm{v}_{\text {grid- }}$

where $v_{\text {grid- } 1}$ is the fundamental component of the grid voltage. The value of $k$ is the output of the PI controller.

\section{PV ENERGY CONVERSION}

The CC-VSI configuration in figure 1 has a capability for PV energy conversion. PV arrays are coupled to the DC bus and parallel to DC-bus capacitors $\left(C_{1}\right.$ and $C_{2}$ ). The amount of active power injected from PV panels is determined by the PV output voltage, which is equal to the DC bus voltage $\left(v_{d c}\right)$. The mathematical model of a single PV module from Fuji Electric (ELR615-160Z) is expressed in

$V=\frac{1}{0.482} \ln \frac{3.281 p_{p}-I}{8.66 \times 10^{-5}}$

where $p_{p}$ is the insolation level. $I$ is the PV short circuit current. $V$ is the PV output voltage. 
For PV array with 1 parallel string and 25 series modules per string, the $p$ - $v$ curve for several levels of irradiance is shown in figure 2. The fluctuation of irradiation leads to the variation of $\mathrm{PV}$ output power.

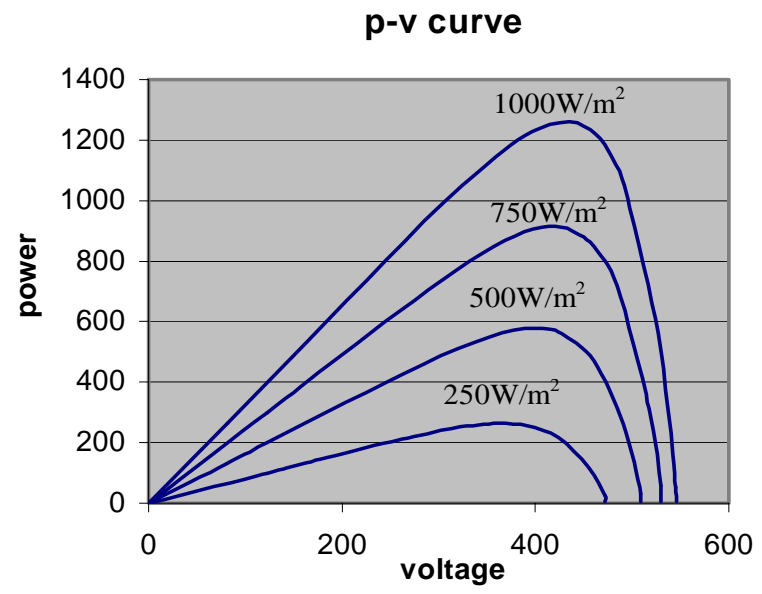

Figure 2. $p$ - $v$ curves of the PV array

The PV modules have to be arranged in an array such that the PV output voltage has to be greater than twice of the peak value of the grid voltage [10]. Otherwise, the CC-VSI is not stable and not able to deliver currents to the grid. On the other hand, there is an upper limit to satisfy voltage insulation requirements of power electronic components.

In addition, there is a MPPT control circuit as a part of the PV system which is independent on the current control loop and the voltage control loop of the CCVSI. The objective of the MPPT controller is to set up the DC-bus reference voltage corresponding to the PV maximum power. As mentioned before, the voltage control loop will maintain the DC-bus voltage at the reference voltage level. If the DC-bus voltage reaches the reference voltage, the PV output power will be at maximum. At the same time, the active power balance among the grid, the load and the PV panels connected to the DC-bus occurs. The active power of the loads is supplied from both the grid and the PV maximum power injection. The fluctuation of irradiation leads to the variation of the DC-bus reference voltage to obtain the PV maximum power.

\section{LOOK-UP TABLE MPPT}

The MPPT is a simple Look-Up Table Method. In this method, a register block is used to store two data arrays, one for the input and the other for the output. Each member of the input data and the output data have to be 1-to-1 correlation. In this case, we store data of insolation (solar irradiance) levels as the input and PV output voltages that generate the maximum power as the output. Hence, we examine $p-v$ curves shown in figure 2 . Then, the voltages corresponding to maximum power for each irradiation are obtained as listed in table 1. Finally, insolation levels and PV output voltages as shown in table 1 are stored together in two data arrays (only first two columns of table 1). The insolation level can be measured using a pyranometer.

Table 1. Insolation level and PV output

\begin{tabular}{ccc}
\hline $\begin{array}{c}\text { Insolation } \\
\left(\mathbf{k W} / \mathbf{m}^{2}\right)\end{array}$ & $\begin{array}{c}\text { PV Output } \\
\text { Voltage (V) }\end{array}$ & $\begin{array}{c}\text { PV } \\
\text { Maximum } \\
\text { Power (W) }\end{array}$ \\
\hline 1 & 430.8 & 1262.5 \\
0.95 & 429.8 & 1191.9 \\
0.9 & 425.0 & 1121.8 \\
0.85 & 422.9 & 1052.1 \\
0.8 & 420.6 & 982.9 \\
0.75 & 416.7 & 914.1 \\
0.7 & 414.4 & 845.9 \\
0.65 & 410.1 & 778.1 \\
0.6 & 408.7 & 711.1 \\
0.55 & 403.8 & 644.6 \\
0.5 & 399.7 & 578.8 \\
0.45 & 393.2 & 513.8 \\
0.4 & 388.1 & 449.6 \\
0.35 & 383.2 & 386.4 \\
0.3 & 375.6 & 324.3 \\
\hline
\end{tabular}

According to the data stored in the register block, the PV output voltage range is limited in between $375.6 \mathrm{~V}$ and $430.8 \mathrm{~V}$. We limit the minimum PV output voltage as well as the DC-bus voltage of the CC-VSI to $375.6 \mathrm{~V}$ for the CC-VSI stability requirement. Therefore, if the insolation level decreases below $300 \mathrm{~W} / \mathrm{m}^{2}$, the MPPT controller commands the DCbus reference voltage to be clamped at $375.6 \mathrm{~V}$. As a result, the PV maximum power can not be achieved because the PV output voltage stays at $375.6 \mathrm{~V}$. The DC-bus maximum voltage is limited to $430.8 \mathrm{~V}$ as well. This voltage is safe for insulation stress of the switching devices.

If the insolation level $p_{p}$ is between two points, a linear interpolation is used to obtain the PV output voltage. For example, if the input $p_{p}$ is greater than $p_{p}(\mathrm{k})$ but less than $p_{p}(\mathrm{k}+1)$, the PV output voltage $V_{p v}$ will be given by

$V_{p v}=V_{p v}(k)+\frac{\left(V_{p v}(k+1)-V_{p v}(k)\right)\left(p_{p}-p_{p}(k)\right)}{p_{p}(k+1)-p_{p}(k)}$ 


\section{SIMULATION RESULTS}

The system shown figure 1 is examined using computer simulation (PSIM ${ }^{\circledR}$ ) to verify the concepts. Table 2 describes the parameter values for the system. The three-phase grid voltages contain harmonics $\left(\mathrm{THD}_{\mathrm{V}}=3.9 \%\right)$, and the mixed loads consist of singleand three-phase linear and non-linear loads (figure 3). The characteristics of the PV modules have been represented in figure 2 .

Table 2. Parameter values for the system under study

\begin{tabular}{lll}
\hline \multicolumn{1}{c}{ Symbol } & \multicolumn{1}{c}{ Description } & \multicolumn{1}{c}{ Value } \\
\hline$v_{g}$ & AC grid voltage, line-line, $r m s$ & $207 \mathrm{~V}$ \\
$f$ & AC line/grid frequency & $50 \mathrm{~Hz}$ \\
$L_{L}$ & Series inductor & $0.92 \mathrm{mH}$ \\
$V_{d c}$ & DC-bus voltage (minimum) & $376 \mathrm{~V}$ \\
$C_{1}=C_{2}$ & DC Capacitors, electrolytic type & $4000 \mu \mathrm{F}$ \\
$L_{i n v}$ & Inverter inductor & $1.52 \mathrm{mH}$ \\
$f_{s w}$ & Target switching frequency & $15.6 \mathrm{kHz}$ \\
\hline
\end{tabular}

The PV output voltage, which equals to the DC-bus voltage as well as PV output power in steady state for solar irradiance of $0.8 \mathrm{~kW} / \mathrm{m}^{2}$ are shown in figure 4 . The pyranometer senses the solar ray and sends the insolation value to the register block. The register block converts the insolation value to a corresponding voltage using its two data array for the DC-bus reference voltage. Then, the DC-bus voltage is adjusted to be equal to the reference voltage level due to a PI controller in the voltage control loop. As a result, the PV array generates the maximum power. It can be seen that the PV output voltage as well as its corresponding maximum power matches to the insolation level.

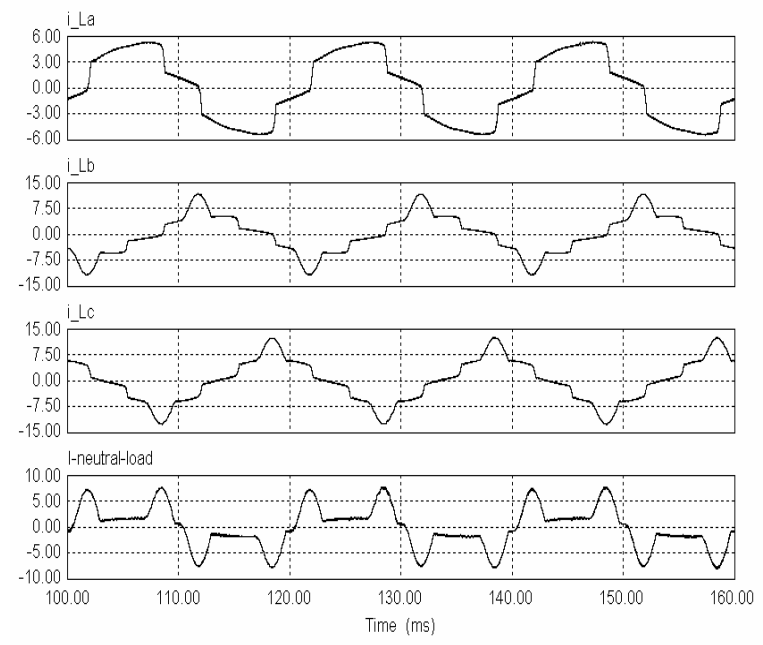

Figure 3. Mixed-load currents (phase a-b-c-neutral)

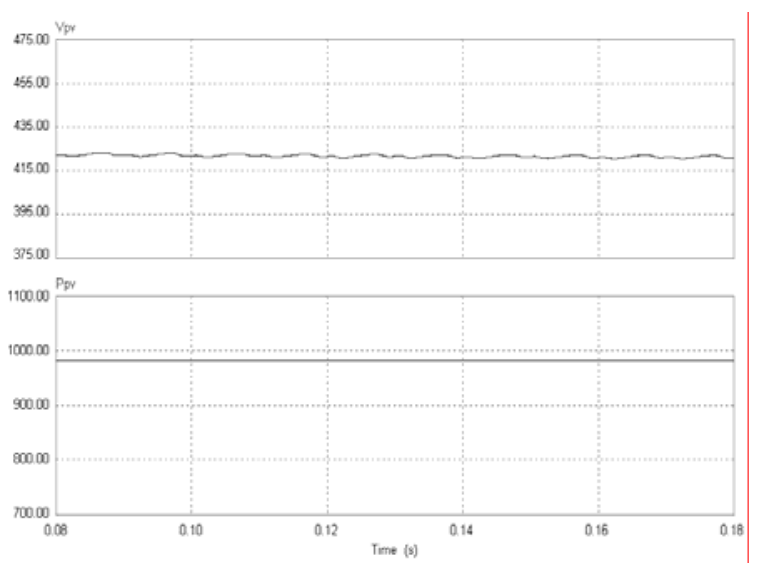

Figure 4. PV output voltage (top) and power (bottom) (for $\mathrm{p}_{\mathrm{p}}=0.8 \mathrm{~kW} / \mathrm{m}^{2}$ )

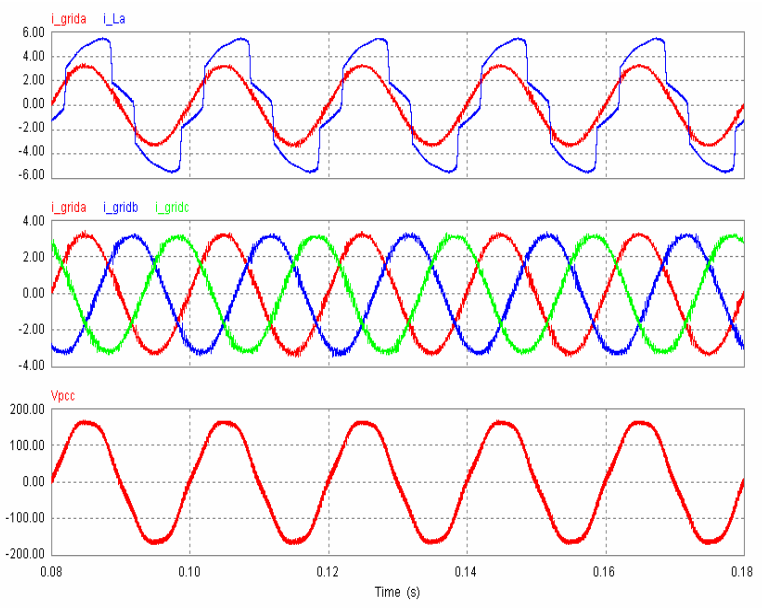

Figure 5. (Top to bottom) The grid and the load currents; three-phase grid currents; the grid voltage (phase A)

Figure 5 illustrates the load current and grid current in phase A. It is obvious that the amplitude of the grid current is smaller than the load current. This is because the load active power is supplied by both the grid and the maximum power extracted from the PV array. Moreover, the grid currents are sinusoidal, balanced and in-phase with the grid voltage due to active filtering operation.

However, when the irradiation level is below $0.3 \mathrm{~kW} / \mathrm{m}^{2}$, the DC-bus voltage is clamped to $375.6 \mathrm{~V}$. The MPPT controller would function improperly and the PV maximum power could not be obtained. Otherwise, the system will be unstable. Figure 6 demonstrates the grid and the load currents in phase A under zero insolation level. The PV does not supply any power and the grid totally supports the load active power. The CC-VSI simply works as a shunt active power filter. 


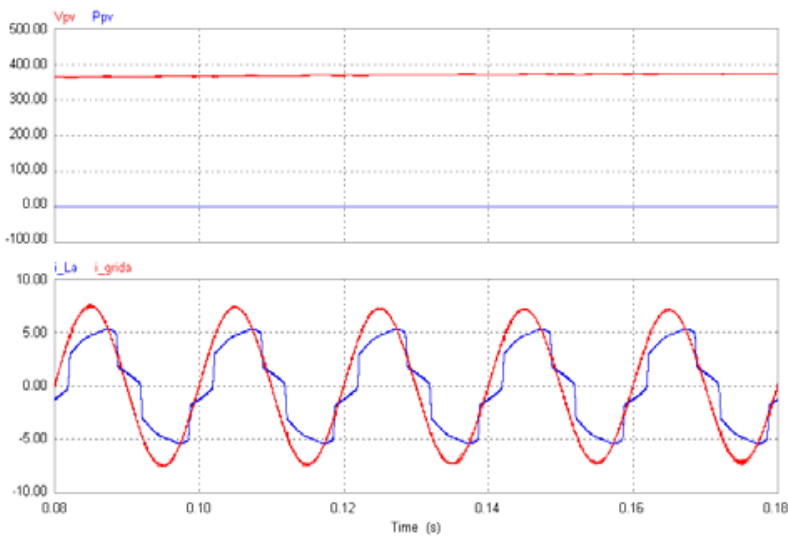

Figure 6. PV output voltage and power under zero insolation level (top); the grid and the load currents (bottom)

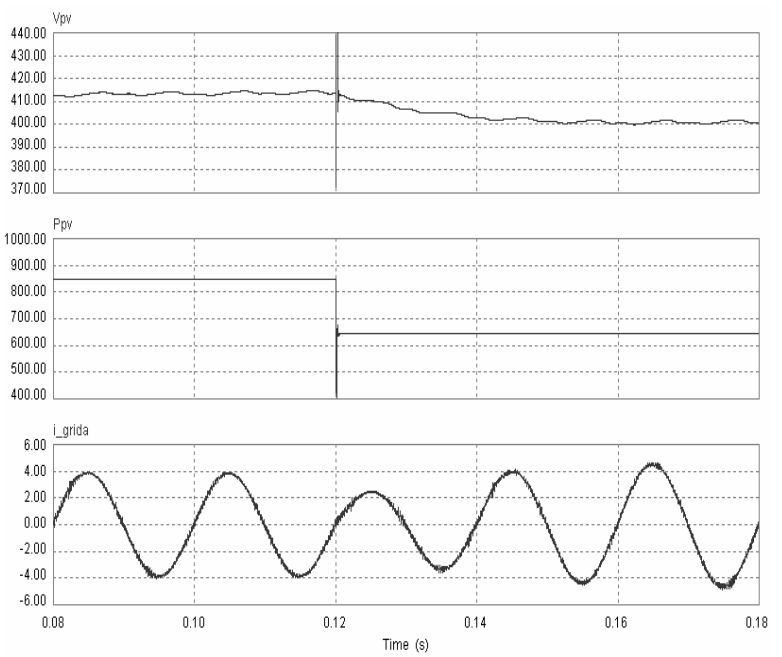

Figure 7. (Top to bottom) PV output voltage; PV output power; the grid current (phase A) when the insolation is changed $\left(0.7 \mathrm{~kW} / \mathrm{m}^{2}\right.$ to $\left.0.55 \mathrm{~kW} / \mathrm{m}^{2}\right)$

Figure 7 shows the PV output voltage and power as well as the grid current when the insolation is changed, in this case from $0.7 \mathrm{~kW} / \mathrm{m}^{2}$ to $0.55 \mathrm{~kW} / \mathrm{m}^{2}$. The MPPT controller responds quickly to reduce the DC-bus reference voltage according to two data arrays. Then, the voltage control loop responds accurately to reach for the new MPP and the new active power balance. The grid currents increase because the $\mathrm{PV}$ power decreases.

\section{CONCLUSION}

This paper describes the capability of a CC-VSI for active filtering and PV energy conversion. It is obvious that both harmonic mitigation and PV energy extraction can be integrated in one CC-VSI, since it only employs a single control strategy using the grid current control loop and the DC-bus voltage control loop. At the same time the MPPT controller independently searches for the maximum power based on 1-to-1 correlation between insolation level and PV output voltage. Those two control loops are able to manage the reactive and harmonic power as well as the active power.

From simulation results, in steady state and dynamic condition, it proves that this system along with the Look-up Table MPPT controller works very well. The CC-VSI can perform as a shunt active power filter as well as a PV energy conversion.

\section{ACKNOWLEDGMENT}

This research is supported by Sophia Lecturing Research Grant, Sophia University, Japan.

\section{REFERENCES}

[1] Borle, L., Zero Average Current Error Control Methods for Bidirectional AC-DC Converters, $\mathrm{PhD}$ Thesis, Electrical and Computer Engineering, Curtin University of Technology, Western Australia, 1999.

[2] Chen, Y., and Smedley, K.M., “A Cost-Effective Single-State Inverter with Maximum Power Point Tracking”, IEEE Transactions on Power Electronics, 2004, 19(5): p. 1289-1294.

[3] Castaner, L., and Silvestre, S., Modelling Photovoltaic System using PSpice, John Wiley \& Sons, 2002.

[4] Wanzeller, M.G. et.al., "Current Control Loop for Tracking of Maximum Power Point Supplied for Photovoltaic Array”, IEEE Transactions on Instrumentation and Measurement, 2004, 53(4): p. 1304-1310.

[5] El-Habrouk, M., M.K. Darwish, and P. Mehta, "Active power filters: a review", Electric Power Applications, IEEE Proceedings, 2000. 147(5): p. 403-413.

[6] Tumbelaka, H.H., L.J. Borle, and C.V. Nayar. "Analysis of a Series Inductance Implementation on a Three-phase Shunt Active Power Filter for Various Types of Non-linear Loads”, Australian Journal of Electrical and Electronics Engineering, Engineers Australia, 2005. 2(3): p. 223-232.

[7] Tumbelaka, H.H., L.J. Borle, C.V. Nayar, and S.R.Lee, "A Grid Current-controlling Shunt Active Power Filter”, Proceedings of ICPE'07, 2007. Daegu, Korea.

[8] Grandi, G., Casadei, D., and Rossi, C., "Direct Coupling of Power Active Filters with Photovoltaic Generation System with Improved MPPT Capability", in IEEE Power Tech Conference, 2003. Bologna, Italy. 
[9] Wu, Tsai-Fu et.al., "PV Power Injection and Active Power Filtering with Amplitude-Clamping and Amplitude-Scaling Algorithms”, IEEE Transaction on Industry Application, 2007, 43(3): p.731-741

[10] Tumbelaka, H.H., L.J. Borle, and C.V. Nayar. “A New Approach to Stability Limit Analysis of a Shunt Active Power Filter with Mixed Non-linear
Loads", in Australasian Universities Power Engineering Conference (AUPEC), Brisbane, Australia: ACPE, 2004, p. ID: 121

[11]Esram T., and Chapman P.L., "Comparison of Photovoltaic Array Maximum Power Point Tracking Techniques", IEEE Transactions on Energy Conversion, 2007, 22(2): p.439-449 